\title{
Molecular Mass Measurement of Intact Ribonucleic Acids Via Electrospray Ionization Quadrupole Mass Spectrometry
}

\author{
Patrick A. Limbach, Pamela F. Crain, and James A. McCloskey \\ Departments of Medicınal Chemıstry and Biochemistry, University of Utah, Salt Lake City, Utah, USA
}

The use of electrospray ionization mass spectrometry for the accurate determination of molecular masses of polynucleotides and small nucleic acids is developed. The common problem of gas phase cation adduction that is particularly prevalent in the mass spectrometric analysis of nucleic acids is reduced through the use of ammonium acetate precipitations and by the addition of chemical additives that compete for adduct ions in solution. The addition of chelating agents such as trans-1,2-diaminocyclohexane- $N, N, N^{\prime}, N^{\prime}$-tetraacetic acid to remove divalent metal ions and trethylamine to displace monovalent cations from the analyte, in conjunction with ammonium acetate precipitation, reduces cation adduction to levels that permit accurate mass analysis (mass errors of less than $0.01 \%$ ) without further complex cleanup procedures. The potential utility of accurate mass measurements of small ribonucleic acids is discussed. (J Am Soc Mass Spectrom 1995, 6, 27-39)

$\mathrm{H}$ istorically, the application of mass spectrometry to oligonucleotides and nucleic acids has been impeded because of the high polarity of these molecules owing to the phosphodiester backbone, which is completely ionized at $\mathrm{pH}>1$. Generally, practical mass spectrometric measurements have been limited to nucleosides and small oligonucleotides [1]. With the recent introduction of new ionzation methods for polar molecules, larger oligonucleotides, including intact nucleic acids, have been analyzed mass spectrometrically (for an earlier review, see [2]). By using matrix-assisted laser desorption methods, Nordhoff et al. [3] have ionized and detected small intact ribonucleic acids including tRNAs and 5S rRNA. Electrospray ionization methods also have been successful in the ionization and detection of intact transfer ribonucleic acids [4]. In all of these studies, the mass spectra were characterized by the presence of abundant cation adduction peaks, and the mass accuracy of these measurements was not reported.

Electrospray ionization [5] now permits the production of completely desolvated ions from extremely polar molecules, which allows the analysis of nucleic acids and their constituents as initially demonstrated by Covey et al. [6]. In solution, solvent acts as a dielectric shield to reduce repulsive Coulombic interactions that result from a net negative charge of -1 at every nucleotide residue. The process of transferring the analyte from solution into the gas-phase results in

Address reprnt requests to James A. McCloskey, Department of Medicinal Chemustry, 311A Skaggs Hall, University of Utah, Salt Lake City, UT 84112 the loss of this Coulombic protection and leads to sequestration of cations present in the solution. These cations serve to reduce the polarity that is due to the highly charged backbone, which thereby improves the production of gas-phase ions. However, dependent on instrument resolving power, the resulting mass spectrum often exhibits broad peaks whose width and complexity reflect the degree of adduction. These adduct peaks also disperse the analyte ion current among multiple cation-containing species within each charge state ion cluster, which thus reduces the sensitivity of the mass measurement.

Accurate mass determination of nucleic acids requires the removal or significant reduction of these cation adducts. In fast-atom bombardment mass spectrometry analysis of oligonucleotides, Grotjahn et al. [7] first proposed and demonstrated the use of triethylammonium salts of oligoribonucleotides to reduce the level of cation adduction. More recently Stults and Marsters [8] clearly demonstrated the utility of precipitation of nucleic acids from $2.5-\mathrm{M}$ ammonium acetate [9] to form ammonium salts that improve electrospray mass spectrometry of these samples. This procedure was carried out on 2-3 nmol of material for precipitation with a concentration of $25-100 \mathrm{pmol} / \mu \mathrm{L}$ of material used for mass spectrometric analysis. In those results, the mass spectrum of a synthetic 77-mer was characterized by the $[\mathrm{M}+\mathrm{Na}]$ ion as the predominant peak within each charge state ion cluster [8]. However, precipitation alone has not proven sufficient as a means to generate measurements of nucleic acids with accuracies that approach the accuracies of peptides and proteins, and the identification of unknown samples 
cannot be established on the basis of putative adduct peaks alone because of the inability to assign the number of cations in the adducts. Little et al. [10] recently demonstrated high performance liquid chromatography (HPLC) cleanup of oligonucleotides before electrospray ionuzation with analysis by Fourier transform ion cyclotron resonance mass spectrometry.

Other methods have been used in matrix-assisted laser desorption ionization (MALDI) to reduce the cation adduction problem. Nordhoff et al. [3] exchanged alkali metal ions agaunst $\mathrm{NH}_{4}^{+}$on an acidactivated polymer to reduce cation complexation. Pieles et al. [11] on a small scale added either drammonium sulfate, diammonium hydrogen citrate, or diammonium-L-tartrate to a mixture of oligonucleotides before analysis, which apparently acts to reduce the cation adduction in their mass spectra.

In this article we report on methods to reduce the salt adduction problem by use of precipitation from ammonium acetate $[8,9]$ on a small scale, in conjunction with the addition of organic additives. This procedure is sufficient to permit the accurate mass measurement of small nucleic acids via a quadrupole mass analyzer. The demonstrated method uses intact transfer ribonucleic acids and small ribosomal ribonucleic acids and achieves mass measurement errors of less than $0.01 \%$. This method is applicable to a range of sample concentrations, and the effectiveness of adduct ion suppression can be monitored rapidly. The use of organic additives minimizes sample loss from multiple desalting operations (e.g., precipitation or HPLC). The procedures described should be useful also for analysis of a number of synthetic polynucleotide derivatives of contemporary interest [12-14].

\section{Experimental}

\section{Materials}

Transfer RNAs $\mathrm{Gly}_{1}(\mathrm{CCC}), \mathrm{Val}_{1}(\mathrm{VAC})$, and $\mathrm{Ser}_{1}(\mathrm{VGA})$ were obtained from Subriden RNA (Rolling Bay, WA). 5S ribosomal RNA was isolated from 50S ribosomal subunits from $E$. coli MRE600 cells purchased from Grain Processing Co. (Muscatine, IA). RNAs were dissolved in deionized water (previously treated with diethyl pyrocarbonate and then autoclaved [15]) to a stock concentration of $250-400 \mathrm{pmol} / \mu \mathrm{L}$. Ethylenediaminetetraacetic acid (EDTA; free acid; 99\% pure), trans-1,2-diaminocyclohexane- $N, N, N^{\prime}, N^{\prime}$-tetraacetic acid (CDTA; free acid; $>99.5 \%$ purity), and nitrilotriacetic acid (NTA; free acid; $99.5 \%$ pure) were obtained from Sigma Chemical Co. (St. Louis, MO). EDTA, CDTA, and NTA were dissolved in concentrated ammonium hydroxide to a concentration of $10 \mathrm{mM}$. This stock solution was diluted one hundredfold for use with the tRNA solutions. Triethylamine (TEA; 99\% pure) was purchased from Aldrich Chemical Co. (Milwaukee, WI) and dissolved in nuclease-free water to a concentration of $0.1 \%$. HPLC grade ammonium acetate was obtained from J. T. Baker (Phillipsburg, NJ) and used without further purification.

\section{Precipitation of RNA}

In general, $40-70 \mu \mathrm{L}$ of stock RNA solution was mixed with $1 / 3$ volume of sterile $10-\mathrm{M}$ ammonium acetate to give a tRNA solution in 2.5-M ammonum acetate [8]. Cold absolute ethanol ( 2.5 volumes) was then added to precipitate the RNAs. Suspensions were stored at -20 ${ }^{\circ} \mathrm{C}$ for about $3 \mathrm{~h}$ and then centrifuged for $15 \mathrm{~min}$ at $12,500 \mathrm{rpm}$. Supernatant was decanted from each tube and the pellet was again washed with about $400-\mu \mathrm{L}$ cold $70 \%$ (aq.) ethanol to reduce the ammonium acetate content. Suspensions were stored about $2 \mathrm{~h}$ at $-20{ }^{\circ} \mathrm{C}$ and then centrifuged at $12,500 \mathrm{rpm}$. Supernatant was decanted and the pellet was dried in a Savant, Speed-Vac centrifuge (Farmingdale, NY) for 20 min with no heat. In those cases in which multiple precipitations were performed, the pellet was dissolved in nuclease-free water before ammonium acetate precipitation. Final concentrations of RNA solutions after precipitation were $300 \mathrm{pmol} / \mu \mathrm{L}$ in $\mathrm{H}_{2} \mathrm{O}$.

\section{Mass Spectrometry}

All electrospray ionization mass spectra were acquired using a PE Sciex (Norwalk, CT) API III + triple quadrupole mass spectrometer. Mass analysis was made by using only $\mathrm{Q} 1$, with $\mathrm{Q} 2$ and $\mathrm{Q} 3$ operating in rf-only mode. The coaxial nebulizer gas (air) pressure was 33 $\mathrm{lb} / \mathrm{in}^{2}$. Curtain gas (nitrogen) flow rate was $0.8 \mathrm{~L} / \mathrm{mm}$. The orifice plate was kept at $60{ }^{\circ} \mathrm{C}$ for analyses. Samples were infused by using a Harvard Apparatus (South Natick, MA) Model 22 syringe pump at a flow rate of $1-2 \mu \mathrm{L} / \mathrm{min}$ at a concentration of 8-10 pmol/ $\mu \mathrm{L}$. In most cases 10 scans were acquired in multichannel analysis (MCA) mode (step size $0.1 \mathrm{u} ; 3$-ms dwell per step) over the mass range $m / z 800-2000(20-35 \mathrm{~s}$ per scan). All RNA solutions were in a $2 \cdot 1$ (isopropanol: $\mathrm{H}_{2} \mathrm{O}$ ) mixture. Solutions of chelating agents and TEA were added in place of water to dilute the stock solution to the working concentrations. Q1 was calibrated first in negative ion mode with polypropylene glycol and then calibrated by using an $8-\mathrm{pmol} / \mu \mathrm{L}$ solution of a purified synthetic deoxyribonucleotide [d(CTCATG)] or a ribonucleotide (CUCAUG). Typical operating voltages were $-3100-\mathrm{V}$ needle voltage (ISV), $-55-\mathrm{V}$ orifice voltage (OR), and $-30-\mathrm{V} \mathrm{Q}_{0}$ voltage (R0).

\section{Molecular Weight Determinations}

Molecular weight calculations of molecular mass from experimental data were made using the HyperMass software included with the Sciex data system. In all cases, calculations of molecular mass from experimental data were made from the most abundant peak in each charge state ion cluster. Reconstructed molecular mass spectra were calculated with a step size of 0.1 over the measured mass range. The MaxEnt recon- 
struction [16] of the $E$. colt $5 \mathrm{~S}$ rRNA electrospray mass spectrum was made by using MassLynx software (VG BioTech, Cheshire, UK). Expected molecular weight values were calculated from the reported tRNA sequence [17] or, in the case of the E. coll rRNA (which contains no posttranscriptional modifications), from the gene sequences [18], by using a molecular weight program developed in the authors' laboratory written by using FaceWare (Urbana, IL) modules and compiled by using Absoft (Rochester Hills, MI) MacFortran II Version 3.2. Determinations of possible compositional isomers were made from a software program written in Microsoft Fortran version 5.0 [19].

\section{Results}

\section{Ammonium Acetate Precipitation}

Precipitation of large oligonucleotides from concentrated solutions of ammonum acetate converts them to the ammonium salt, which results in significant improvements in signal-to-noise ratios in electrospray mass spectrometry [8]. tRNA ${ }^{\text {Val1 }}$, a class I tRNA (76 nucleotides, $\mathrm{nt}$ ), was precipitated multiple tımes from
2.5-M ammonium acetate, and a dramatic improvement in spectral intensity can be seen in Figure 1a-c as a more than tenfold increase in analyte ion current is realized. The reduction in cation adduction by ammonium replacement shifts the charge state distribution to a higher value as well as increases the number of charge states detected. Although the peak widths, which are a measure of the total number of cation adducts, do not decrease with increasing ammonium acetate precipitations (each charge state was approximately $9 \mathrm{~m} / \mathrm{z}$ units at half-height for all precipitations), the ion current is shifted within each charge state to a lower mass. RNA yields for repeated precipitations were typically $96 \%$ yield after one precipitation, $83 \%$ (of initial amount) after a second precipitation, and 73\% (of initial amount) after a third precipitation.

For tRNA ${ }^{\text {Val1 }}$ (calculated $M_{\mathrm{r}}=24,680.96$ ) that was precipitated once, the reconstructed molecular mass is 24,735 u (133 u wide at half-height), whereas after three precipitations the reconstructed molecular mass becomes $24,716 \mathrm{u}$ (123 u wide at half-height). Unfortunately, precipitation alone for large polynucleotides is insufficient to remove cation adduct species to provide accurate mass values, and some other means for this reduction must be employed.

a

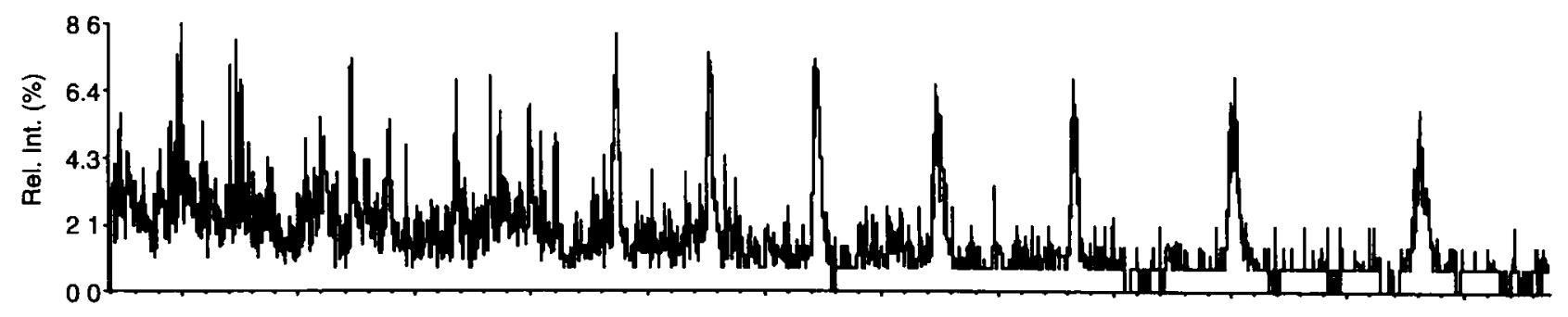

b

9,055

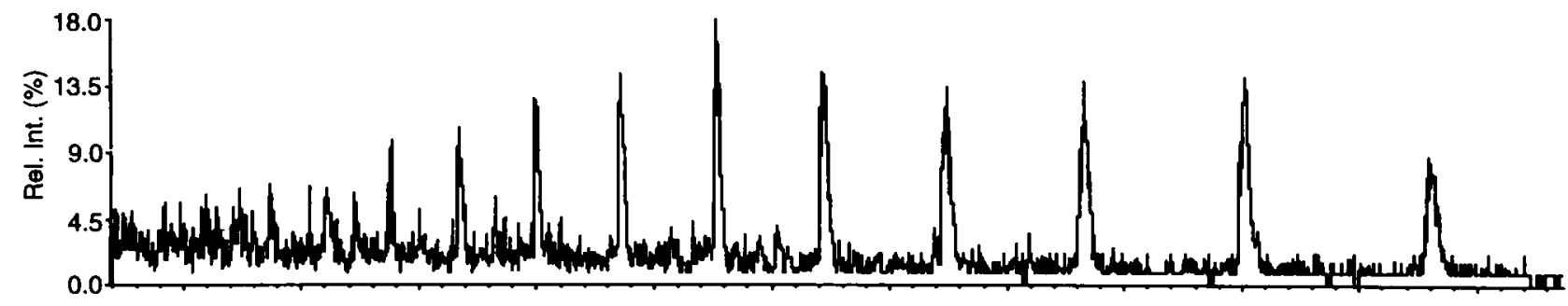

c

50,394

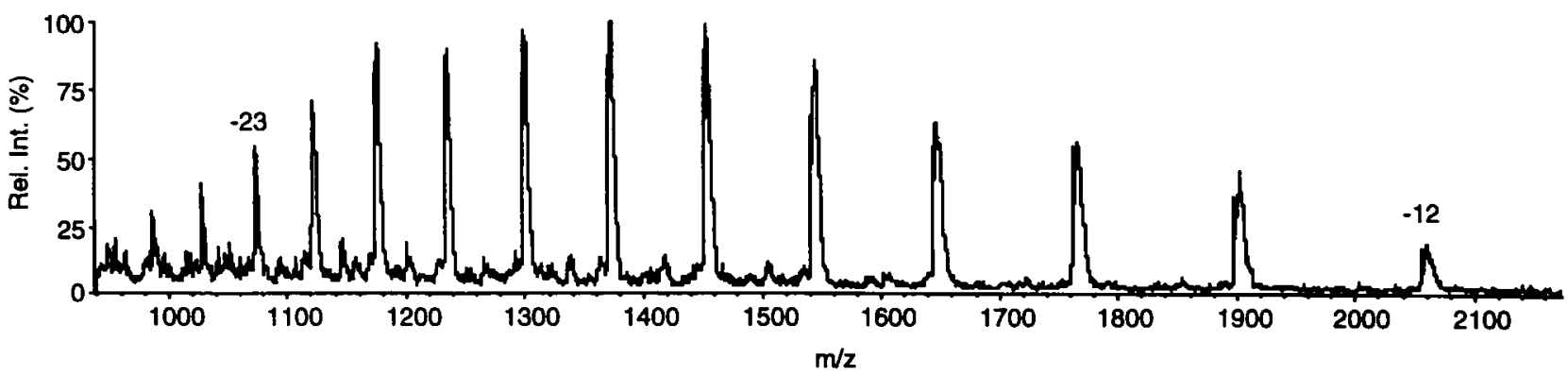

Figure 1. Electrospray mass spectrum of $E$. coll $t R N A^{V a l 1}$ that shows the effect of $t R N A$ precipitation from 2.5-M ammonium acetate. (a) One precipitation, (b) two precipitations; (c) three precipitations. 


\section{Addition of Chelating Agents}

Although precipitation is useful both in reducing the extent of monovalent cation adduction and in increasing the analyte ion current delivered to the mass spectrometer, the highly charged polynucleotide backbone still retains a large amount of adducts to stabilize the Coulombic forces. Transfer RNAs are known to have large binding affinities for certain transition metals [20]. Typically, $\mathrm{Mg}^{++}$is found naturally in tRNAs to provide for proper secondary and tertiary structure. Such metal ions also may be involved in adduction in the same manner as $\mathrm{Na}^{+}$and $\mathrm{K}^{+}$, thus increasing the mass of the nucleic acid, and some means for their removal is also necessary. There are several organic chelating agents that have a high binding affinity for divalent metal ions, and those used in the present study are shown in Table 1.

The effect of adding two of these compounds (NTA and CDTA) to a solution of $2 \times$ precipitated $E$. coli tRNA ${ }^{\text {val1 }}$ before analysis is shown in Figure 2. In the data shown in Figure 2a, $1 \mathrm{nmol}$ of NTA was added to $300 \mathrm{pmol}$ of tRNA. The improvement in sensitivity is threefold as compared to the twice precipitated solution alone (Figure $\mathrm{lb}$ ), and peak widths are reduced from 9 to $4 \mathrm{~m} / \mathrm{z}$ units (half-heights). Results from the addition of 1 nmol of EDTA to 300 pmol of tRNA (data not shown) were similar to those for the addition of NTA. Figure $2 b$ shows the effect of the addition of 1 nmol of CDTA to E. coli tRNA ${ }^{\text {Vall }}$. In this case, sensitivity is five times higher and peak widths are reduced to $2 \mathrm{~m} / z$ units (half-height). It should be noted that although a molar excess of chelating agent was added to the nucleic acid mixture, each nucleic acid molecule has at least 75 sites that can bind a cation, and the extent of adduction at each phosphodiester (or other) site before analysis is unknown.

The combination of precipitation and addition of metal chelators typically reduces peak widths (halfheight) of the individual charge state from clusters of $10 \mathrm{~m} / z$ units to less than $2 \mathrm{~m} / \mathrm{z}$ units and reduces the error in mass determination to less than $0.01 \%$. The optimal amount of chelator added depends on the initial condition of the nucleic acid and the number of times it was precipitated from $2.5-\mathrm{M}$ ammonium acetate. For instance, with $E$. coll $\mathrm{TRNA}^{\mathrm{Val1}}$, one ammonium acetate precipitation requires $5 \mathrm{nmol}$ of CDTA for accurate mass measurement (data not shown); after two precipitations only $3 \mathrm{nmol}$ of CDTA are needed (Figure 3), and with three precipitations only $1 \mathrm{nmol}$ was sufficient for accurate mass measurement (data not shown). It should be noted that addition of a chelating agent will improve sensitivity to a limit after

Table 1. Formation constants for metal complexes with organic ligands [27] (values are reported as $\log K_{1}$ )

\begin{tabular}{lccc}
\hline & CDTA & EDTA & NTA \\
\hline \hline $\mathrm{Mg}^{++}$ & 1041 & 864 & 536 \\
$\mathrm{Na}^{+}$ & & 166 & 215 \\
\hline
\end{tabular}

which addition of more chelating agent results in formation of adducts from the chelating agent with a concomitant reduction in the sensitıvity. In all the experiments reported here, CDTA was found to be the most effective chelating agent, which is not surprising considering its high binding affinity for divalent metal ions (Table 1).

\section{Addition of Triethylamine}

We also found that addition of TEA produces results similar to CDTA addition, presumably by displacement of cations by competition for phosphate coordination sites. Figure 4 demonstrates the advantages of TEA for salt removal. Various amounts of $0.1 \%$ TEA solutions were added to $300 \mathrm{pmol}$ of $E$. coll tRNA $\mathrm{TAll}^{\text {val }}$ that was precipitated once from $2.5-\mathrm{M}$ ammonium acetate. The addition of $5 \mu \mathrm{L}$ of TEA solution (Figure 4a) improves the signal-to-noise ratio twofold as compared to precipitation alone. The addition of 10- (Figure $4 \mathrm{~b}$ ) or $15-\mu \mathrm{L}$ (Figure $4 \mathrm{c}$ ) amounts of TEA solution further improves the signal-to-noise ratio: the most dramatic increase occurs with the addition of $15 \mu \mathrm{L}$. However, addition of TEA alone was not sufficient to shift the majority of the ion current to the unadducted species within each charge state cluster: this is similar to the ammonium acetate precipitation results and unlike the effect from the addition of CDTA. For instance, the experimentally determined value (by using HyperMass) after addition of $15 \mu \mathrm{L}$ of TEA is $24,695.26$ $u$, a mass error of $\left(5.8 \times 10^{-2}\right) \%$. As with the use of chelating agents, the addition of excess TEA eventually results in the formation of $\mathrm{TEAH}^{+}$adducts and a reduction in sensitivity.

\section{Addition of Chelating Agents and Triethylamine}

The combination of CDTA and TEA added to the nucleic acid mixture was extremely effective at reducing mono- and divalent cation adduction and resulted in the most accurate mass measurements. Figure 5 is an example of a mass spectrum derived from the addition of $2.5 \mathrm{nmol}$ of CDTA and $10 \mu \mathrm{L}$ of TEA solution to 300 pmol of $E$. coli $\mathrm{tRNA}^{\text {vall }}$. Very high sensitivity is obtainable and the amount of cation adduction is reduced compared to either additive alone (cf. Figures 3 and 4). Other tRNAs also were analyzed to characterize the effectiveness of this CDTA-TEA "cocktail" for accurate mass measurements. tRNA ${ }^{\text {Gly1 }}$ is another class I tRNA (74 nt) and tRNA ${ }^{\text {Ser1 }}$ is a class II tRNA ( $88 \mathrm{nt}$ ). Each tRNA was precipitated once and $1 \mathrm{nmol}$ of CDTA and $5 \mu \mathrm{L}$ of TEA solution were added before analysis. Figure 6 and Table 2 demonstrate the results of adding this mixture to each tRNA. All tRNAs were measured with errors less than $0.01 \%$ (standard deviations less than $3 \mathrm{u}$ ) and with vastly improved ion sensitivities as compared to either additive alone or precipitation alone.

With the reduction in peak widths for individual 
a

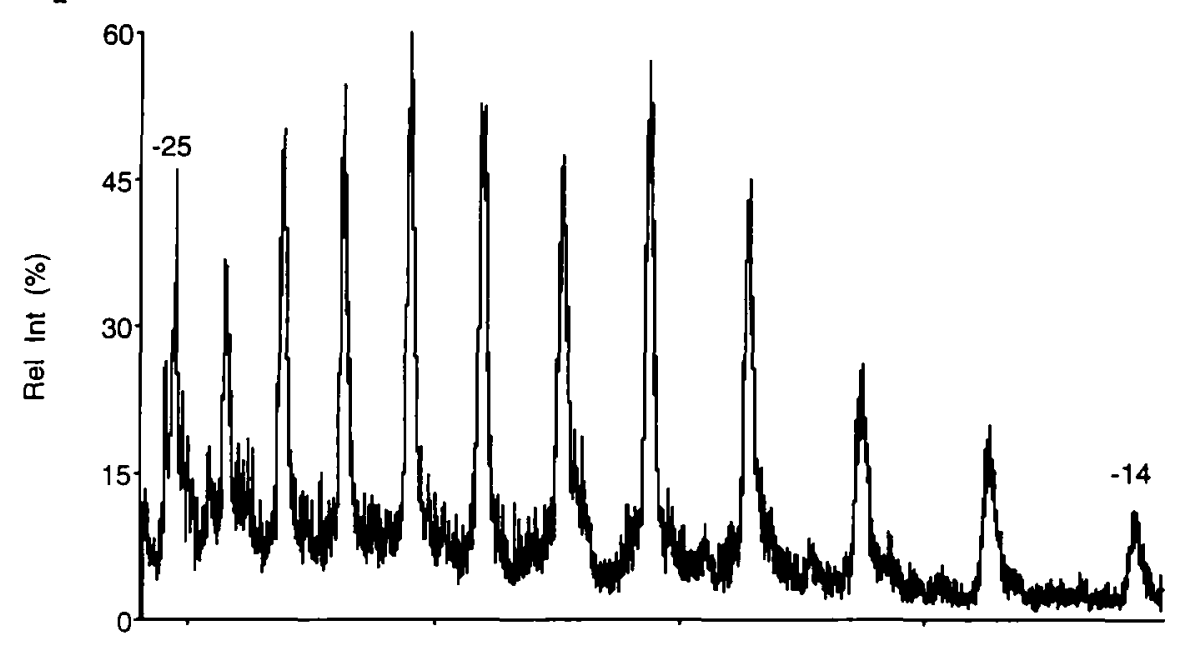

b

49,649

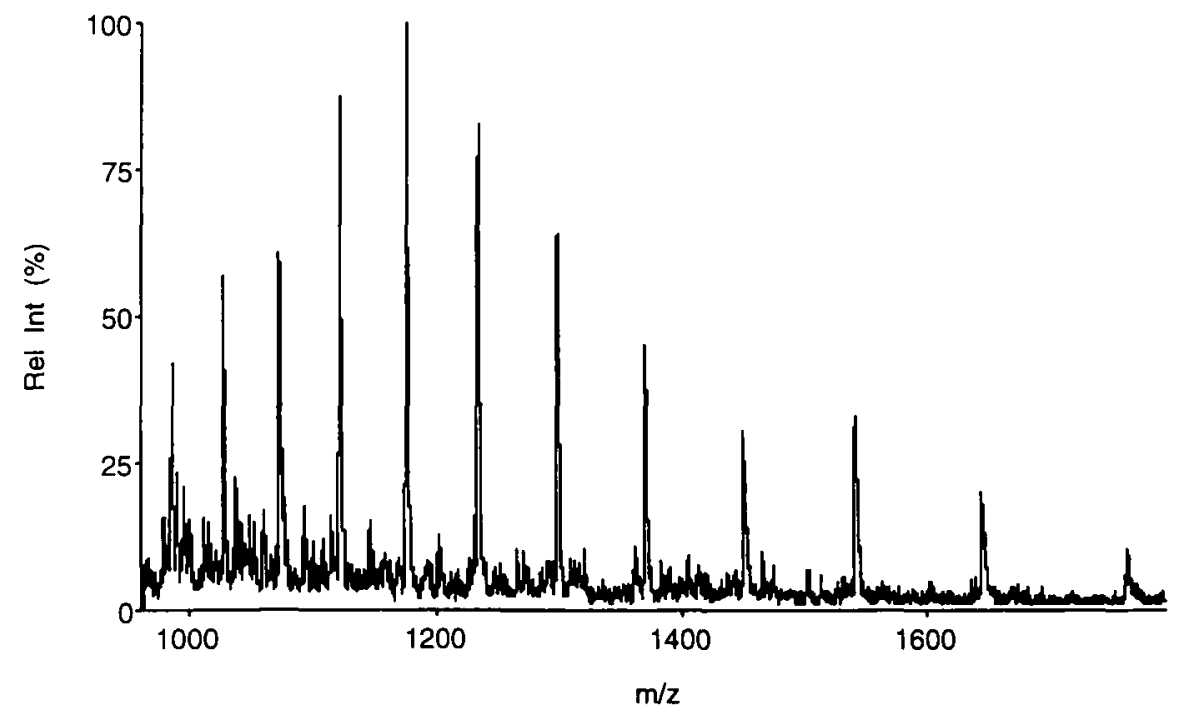

Figure 2. Effect on the electrospray mass spectrum of $E$ coll $\mathrm{tRNA}^{\mathrm{vall}}$ of the addition of chelatung agents to a sample that was precipitated from 25-M ammonum acetate two times. (a) Addition of 1-nmol NTA to 300-pmol tRNA. Expermentally determined Hypermass values $M_{r}=24,779.09 u$; s.d 1087 (b) Addition of 1-nmol CDTA to 300-pmol tRNA. Experimentally determined Hypermass values $M_{\mathrm{r}}=24,681.09 \mathrm{u}$, s d 157

charge states, the use of mass spectrometers with higher resolving powers is less necessary to analyze mixtures of nucleic acids. Figure 7 again compares the effect of adding TEA alone (Figure 7a), CDTA alone (Figure $7 \mathrm{~b}$ ), or the two in combination (Figure $7 \mathrm{c}$ ) to an equimolar mixture of $t R N A^{\mathrm{Gly} 1}$ and $t R N A^{\mathrm{Val} 1}$. The charge states are easily assignable with a quadrupole mass spectrometer except those ions below $m / z$ 950, which differ by $1 \mathrm{~m} / z$ unit or less. Mass accuracies for each tRNA component in the mixture are comparable to those obtained for each tRNA individually.

As a test of this method for even larger nucleic acids, a sample of E. coli $5 S$ ribosomal RNA (120 nt) was precipitated once from 2.5-M ammonium acetate, and $500 \mathrm{pmol}$ of CDTA and $10 \mu \mathrm{L}$ of TEA solution were added to the rRNA sample before electrospray-
Ing. Without the addition of either additive, no discernible mass spectrum could be acquired. However, the addition of CDTA and TEA permitted accurate mass measurement of the rRNA (Figure 8). The two peaks detected correspond to transcripts of the two $5 S$ rRNA genes that occur in E. coll MRE 600 [18]. The lower mass, lower abundance ion series corresponds to the $E$. coli MRE 600 minor gene and the higher mass, higher abundance ion series corresponds to the MRE 600 major gene. The calculated masses for each gene product are shown. The measured masses for each are $38,817.85$ and $38,856.75 \mathrm{u}$, which correspond mass errors of $\left(5.9 \times 10^{-3}\right)$ and $\left(4.0 \times 10^{-3}\right) \%$, respectively. The only differences in the two RNAs are nucleotide changes of $G \rightarrow U$ at residue 13 and $U \rightarrow C$ at residue 92. After formation of ammonium salts and addition of 


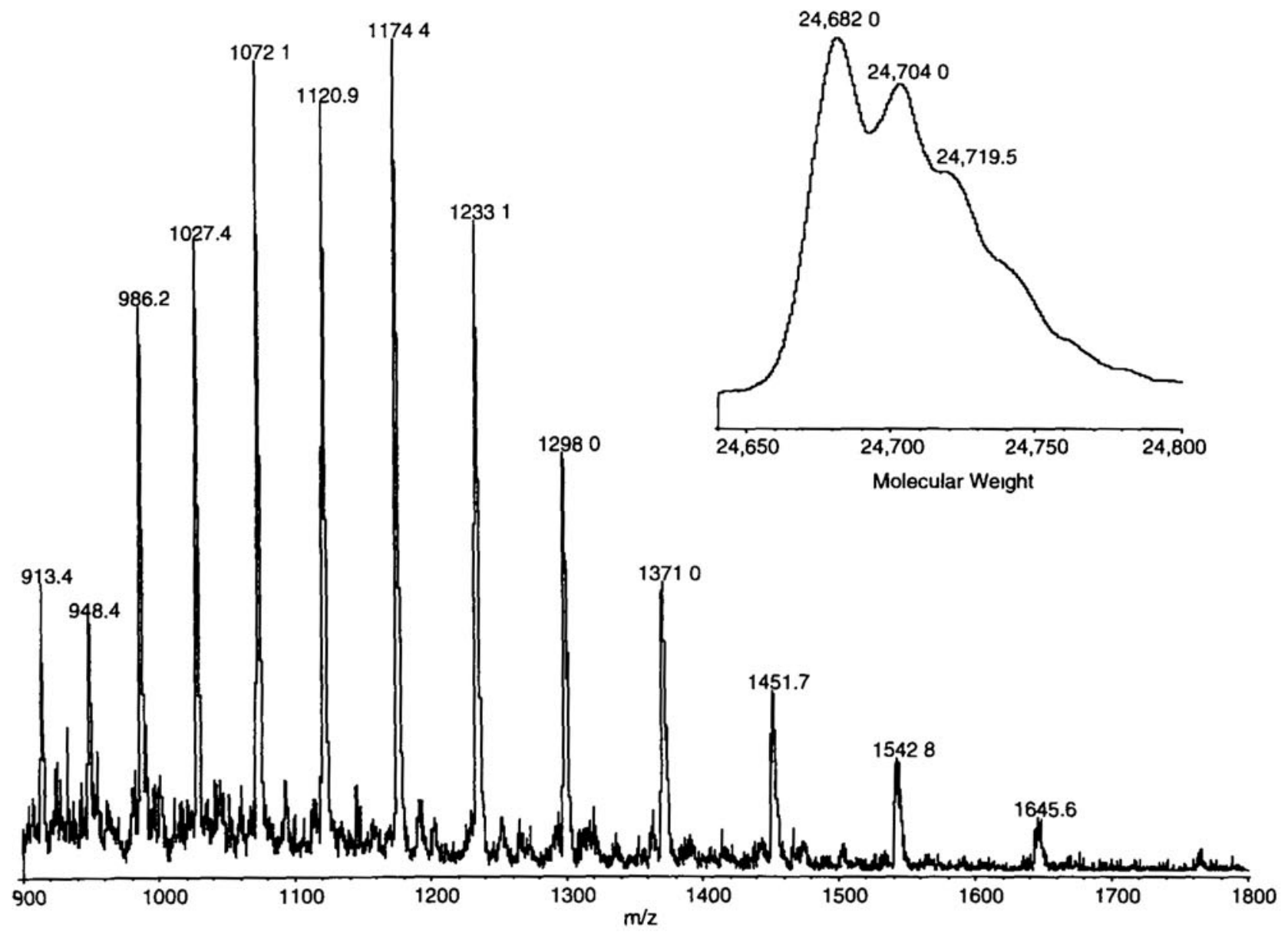

Figure 3. Optimal conditions for accurate mass analysis of $E$ colt $t R N A^{\text {Val1 }}$ by using chelatıng agent (CDTA). Ten scans were acquired in MCA mode and the data were smoothed three times Average peak width (at half-height) of individual charge states is $3 \mathrm{~m} / \mathrm{z}$ units, although there is sufficient resolution to distinguish sodium adduct peaks. Inset reconstructed molecular mass of analyte. Measured $M_{\mathrm{r}}=24,681.24 \mathrm{u}$ with standard deviation of 1.50 (determined by using Hypermass).

the additives, these differences are easily distinguished and measured by using a quadrupole mass spectrometer.

\section{Discussion}

\section{Reduction of Adduct Ion Intensities}

The phosphodiester backbone of oligonucleotides in solution is negatively charged $\left(p K_{a} \sim 1\right)$ and as a consequence has a high affinity for free cations that are present. Upon ionization, these cations (e.g., $\mathrm{Na}^{+}$, $\mathrm{Mg}^{++}$) produce adduct species with polynucleotides and, when present in excess, result in reduced ionization efficiency. Experimentally, several precautions must be heeded. It is important to work with ultrapure grade solvents that are stored in containers that do not produce salt contamination; in particular, glass containers should be avoided. Capillaries used to transfer the sample to the mass spectrometer are a source of contamination and should be kept clean. To reduce the background salt content in electrospray mass spectra from oligonucleotides, we have found it necessary to replace the fused capillary provided with the Sciex instrument with $100-\mu \mathrm{m}$ o.d. polyether ether ketone (PEEK) tubing, which is easier to clean and retains much less salt during analysis.

Precipitation from concentrated ammonium salt concentrations with alcohol is the most effective way to concentrate and recover nucleic acids $[9,21]$, concomitant with conversion to the ammonium salt. The minimum amount of material that can be precipitated from $1 \mathrm{~mL}$ of solution is 50 (DNA) or $100 \mathrm{ng}$ (RNA) [21], and the sample can be retained in a single microtube throughout all procedures. The sample preparation time used in the present study (about $5 \mathrm{~h}$ ) does not represent the minimum time for sample precipitation(s), which can be reduced to about $10 \mathrm{~min}$ if the concentration of nucleic acid is greater than $10 \mathrm{mg} / \mathrm{mL}$ [22]. Overnight precipitation is recommended when the amount of sample is not known [23]. Nonetheless, multiple samples can be processed at one time, which makes precipitation from ammonium acetate a potentially rapid method of desalting oligomers greater than about 10 residues.

Addition of the chelating agents to solutions of 


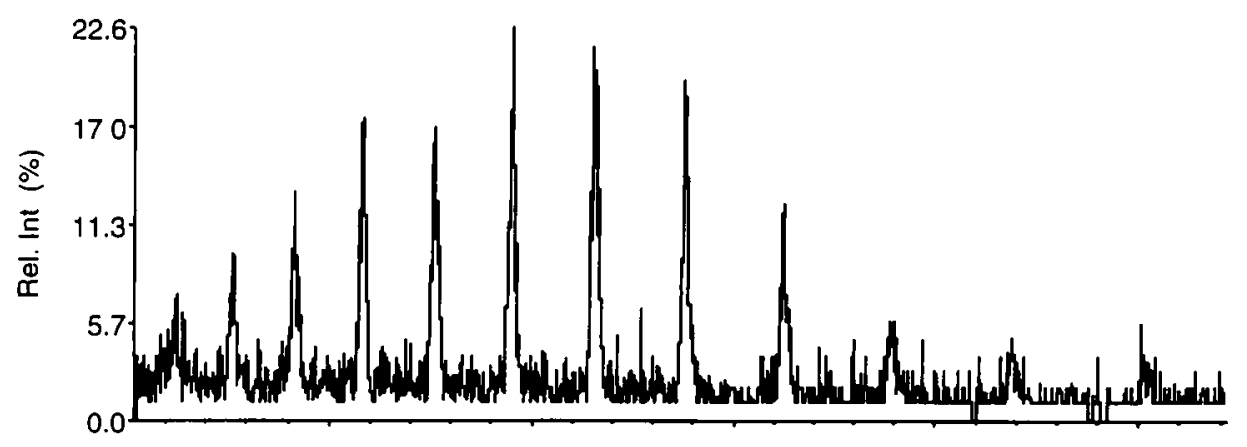

b

10,957
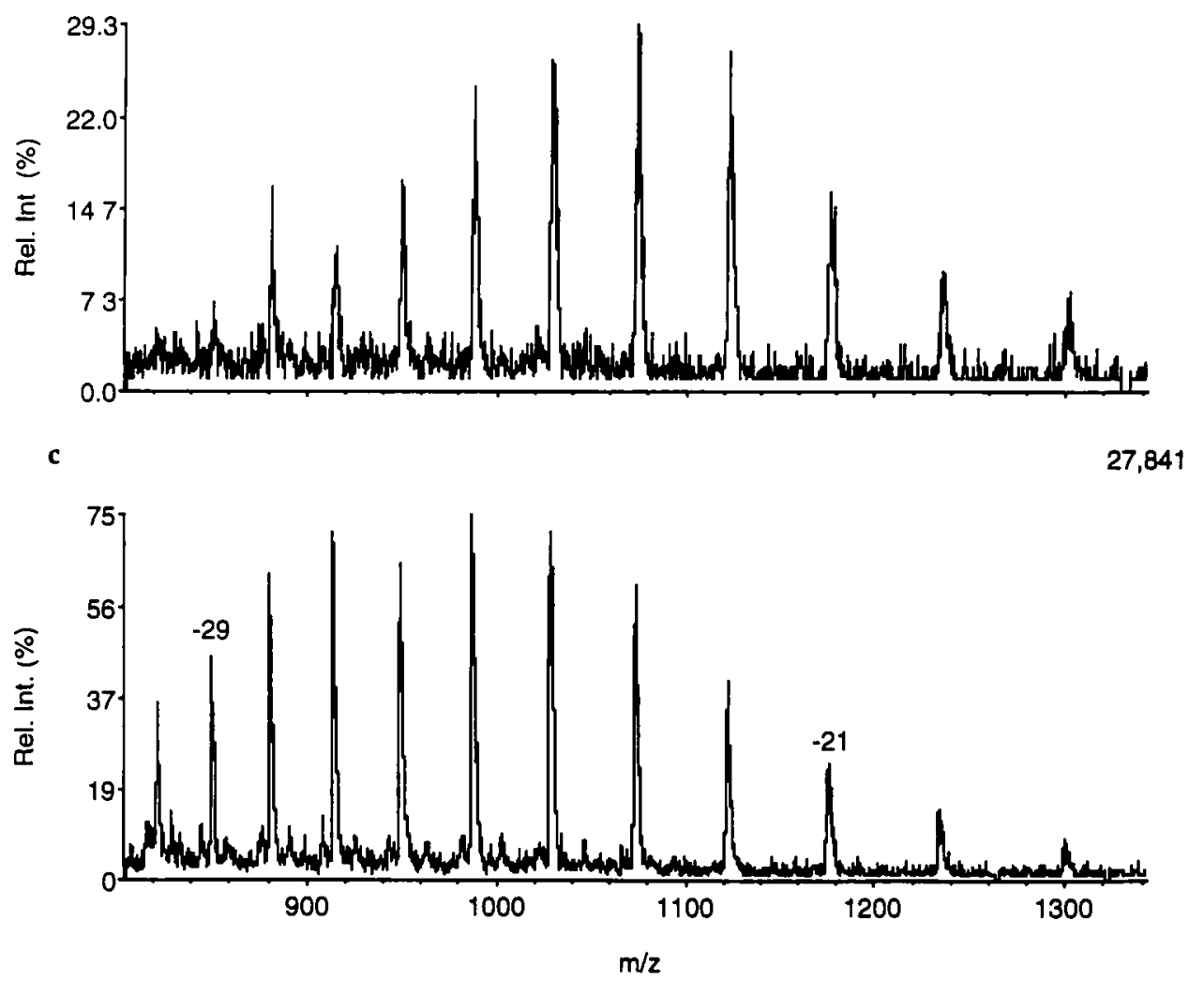

Figure 4. Effect on the electrospray mass spectrum of $E$. coll $t_{R N A}{ }^{v a l 1}$ of the addition of triethylamine (TEA) to a sample that was precipitated once from 2.5-M ammonum acetate. (a) Addition of $5 \mu \mathrm{L}$ of $0.1 \%$ TEA. Experimentally determined Hypermass values $M_{\mathrm{r}}=24,758.61 \mathrm{u}$, sd. 6.45. (b) Addition of $10 \mu \mathrm{L}$ of $0.1 \%$ TEA. Experımentally determined Hypermass values $M_{\mathrm{r}}=24,718.46 \mathrm{u}$, s.d 1.90 . (c) Addition of $15 \mu \mathrm{L}$ of $0.1 \%$ TEA Experimentally determined Hypermass values $M_{\mathrm{r}}=24,695.26$ u; s.d. 118 .

nucleic acids results in both an improvement in the signal-to-noise ratio of the mass spectrum as well as reduction of mass spectral peak widths by removal of excess adducted cations. Cations essential for tRNA function may be classified as those required for general folding of the tRNA (weak binding) and those that preserve specific features of conformation (strong binding) [20]. It has been found that there are $23 \pm 5$ weak binding sites in tRNA with binding constants for $\mathrm{Mg}^{++}$ of $10^{3}[24,25]$ and between 4 and 6 strong binding sites with binding constants for $\mathrm{Mg}^{++}$of $10^{5}$ [26]. In these experiments we found that CDTA was more effective than other agents for the reduction of cation adduction. Not surprisingly, CDTA has the strongest binding affinity for $\mathrm{Mg}^{++}$of all the common chelating agents [27]. Presumably, the CDTA effectively competes for both free $\mathrm{Mg}^{++}$ions in the solution as well as with those already bound to the tRNA. Denaturation of the sample by gentle heating (to expose more of the backbone to CDTA) provided no additional improvement to the mass spectra. In the case of synthetic polynucleotides, divalent metal ions are much less 


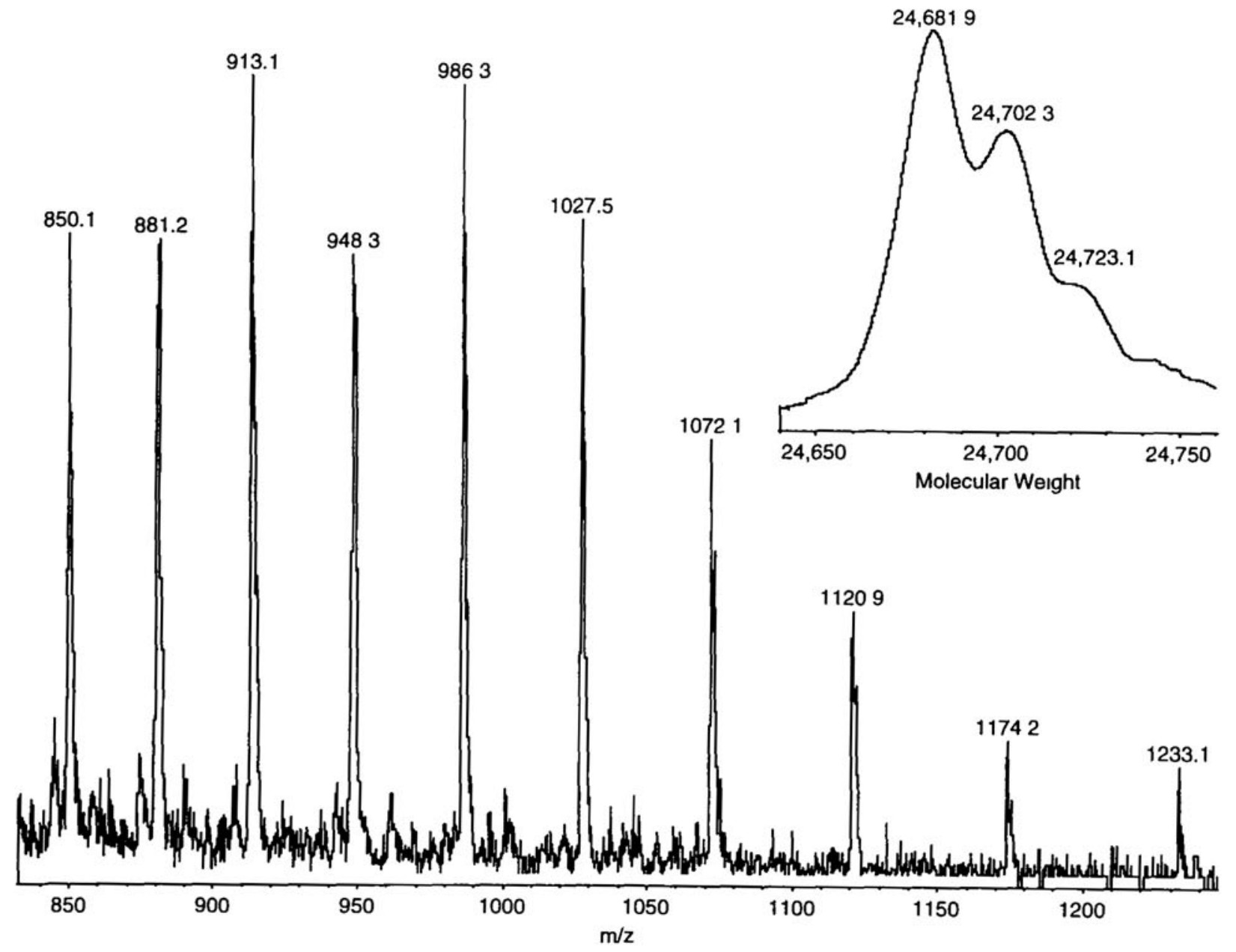

Figure 5. Optimal conditions for accurate mass analysıs of $E$ colı $\mathrm{RRNA}^{\mathrm{Vall}}$ by using a mixture of chelatıng agent (CDTA) and triethylamine (TEA) Ten scans were acquired in MCA mode and the data were smoothed three times. Average peak width (at half-height) of individual charge states is $2 \mathrm{~m} / z$ units, although there is sufficient resolution to distinguish sodium adduct peaks. Inset. Reconstructed molecular mass of analyte Measured $M_{\mathrm{T}}=24,682.19 \mathrm{u}$ with standard deviation of 1.58 (determined by using Hypermass)

likely to be present, and the principal salt problem is usually due to $\mathrm{Na}^{+}$and $\mathrm{K}^{+}$.

In addition to the use of chelating agents, we also found that triethylamine effectively competes with free monovalent cations for nucleotide binding sites. Most likely, $\mathrm{TEAH}^{+}$replaces $\mathrm{Na}^{+}$(and other monovalent cations) and forms a TEAH ${ }^{+}$salt via a phosphate-ion pair. TEA can then be lost as a neutral from the ion pair during desolvation, which leaves behind a (net) neutral phosphate (in which $\mathrm{H}^{+}$is shared between phosphate and other basic sites [28]). Alternatively, $\mathrm{TEAH}^{+}$may be expelled, which results in a gas-phase phosphate anion. Because desalting of RNAs by multiple ammonium acetate precipitations or HPLC results in some sample loss, the ability to reduce cation adduction by manipulating the analyte solution at a relatively early stage provides a simple and effective method for generation of mass spectra of high quality.

Physical methods to reduce the salt content of nucleic acids include HPLC or membrane dialysis. HPLC is suitable for limited desalting when large amounts of material are available (and is recommended for small oligodeoxyribonucleotides, e.g., 10-mer and below [29], which are not efficiently precipitated with alcohol). We do not, however, recommend HPLC for desaltıng RNA, which is exceptionally sensituve to adventitious endonucleolytic cleavage from heavy metal ions and extrinsic nucleases [23], for example, present in or on equipment not specially treated and reserved for nucleic acid work. In addition, sample losses are, in our experience, not inconsequential for small (e.g. picomole) sample amounts. For these reasons, we have not compared HPLC directly against the chemical methods reported here. We note that the Na content of a commercial tRNA sample was reduced from $23-45 \mathrm{Na}$ atoms to $0-8$ by HPLC [10], which is not as effective as the chemical approach used in the present study. Membrane dialysis also may be effective, although sample losses are again nontrivial and, particularly for RNA, degradation can occur. Both of these methods typically require more material than would be necessary otherwise for mass spectrometric analysis alone, 

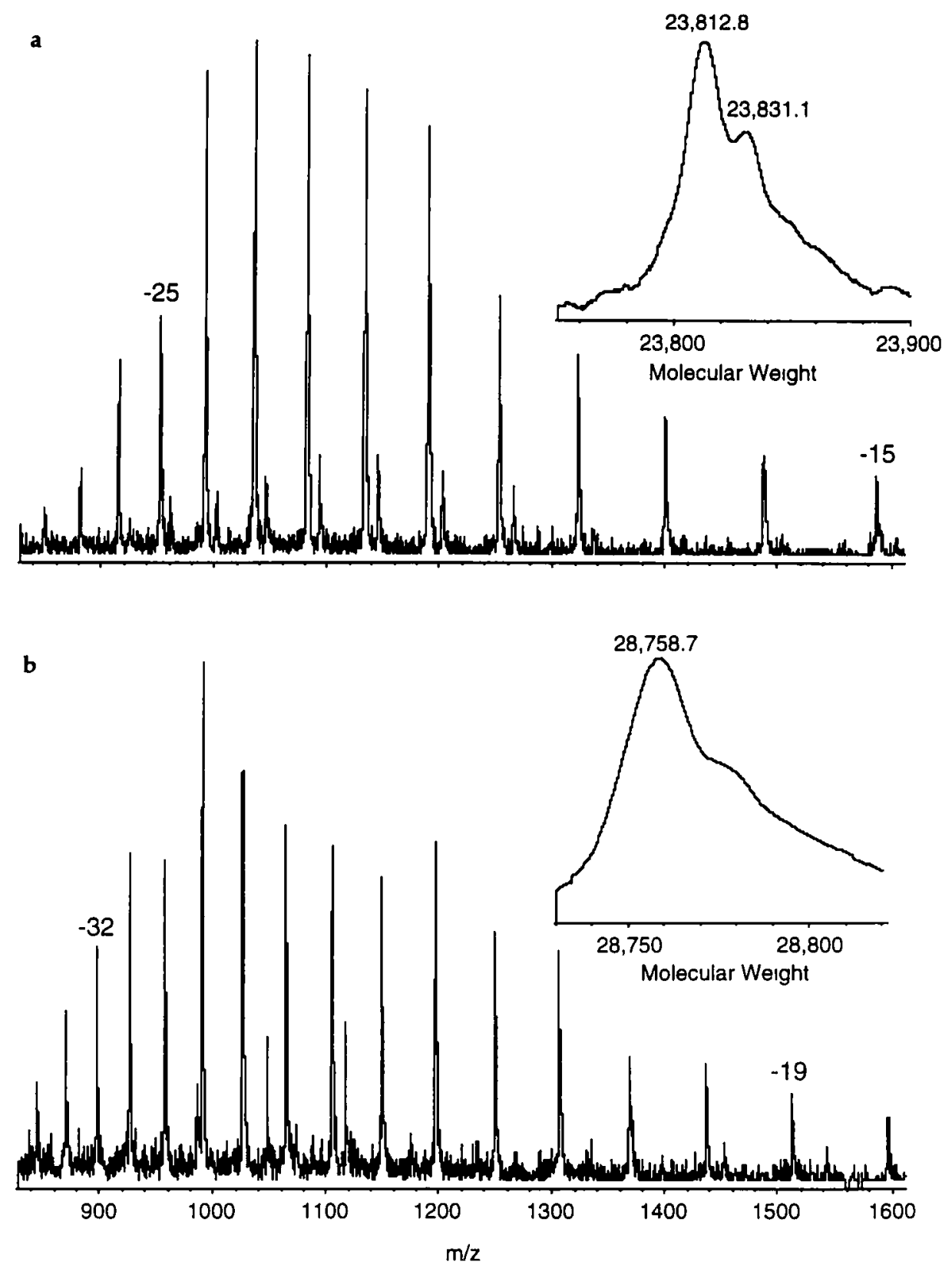

Figure 6. Electrospray mass spectra of (a) tRNA $\mathrm{Rly}^{\mathrm{Gl}}$ and (b) $t \mathrm{RNA}^{\mathrm{Serl}}$ under optımal salt reduction conditons See Table 2 for calculated and found molecular masses and corresponding mass errors.

Table 2. Experımental values for nucleic acid molecular mass measurements ${ }^{a}$

\begin{tabular}{lccc}
\hline E coll nucleıc acıds & $M_{\mathrm{r}}$ calculated & $M_{\mathrm{r}}$ found & $\begin{array}{c}\text { \% Error } \\
\left(\times 10^{-3}\right)\end{array}$ \\
\hline \hline tRNA $^{\text {Gly } 1}$ & 23,81136 & 23,81336 & 84 \\
tRNA $^{\text {Val1 }}$ & $24,680.96$ & 24,68124 & 11 \\
tRNA $^{\text {Ser } 1}$ & 28,75760 & 28,75880 & 42 \\
5S rRNA & & & \\
Major component & $38,853.40$ & 38,85494 & 40 \\
Minor component & 38,81436 & $38,816.65$ & 59 \\
\hline
\end{tabular}

${ }^{a}$ Calculated values are derived from reported tRNA sequences [17] or from the reported 5S rRNA gene sequences [18] thus hindering their usefulness for many biological problems in which the sample amount is limited.

\section{Utility of Nucleic Acid Mass Measurements}

As a consequence of the ability to remove cations from polynucleotide solutions, sufficiently accurate mass measurements can be achieved routinely to permit a range of practical applications to both synthetic and natural polynucleotides. For example, Table 3 lists all class I and class II tRNAs from E. coli and shows calculated molecular mass, modification load (i.e., the mass component due to modification), and chain length. An examination of the tRNA sequences of all $E$. coli class I tRNAs finds that these nucleic acids all contain the four major nucleosides within well defined 
a

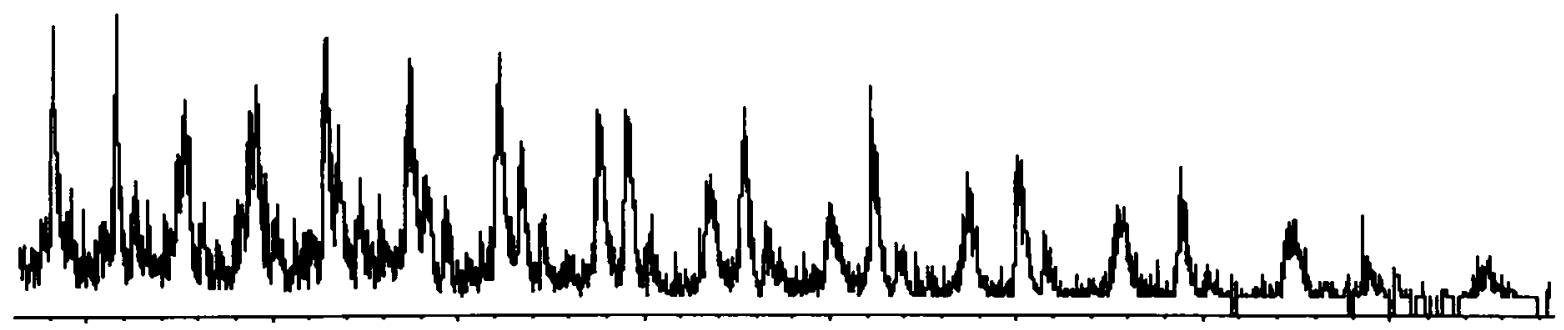

b
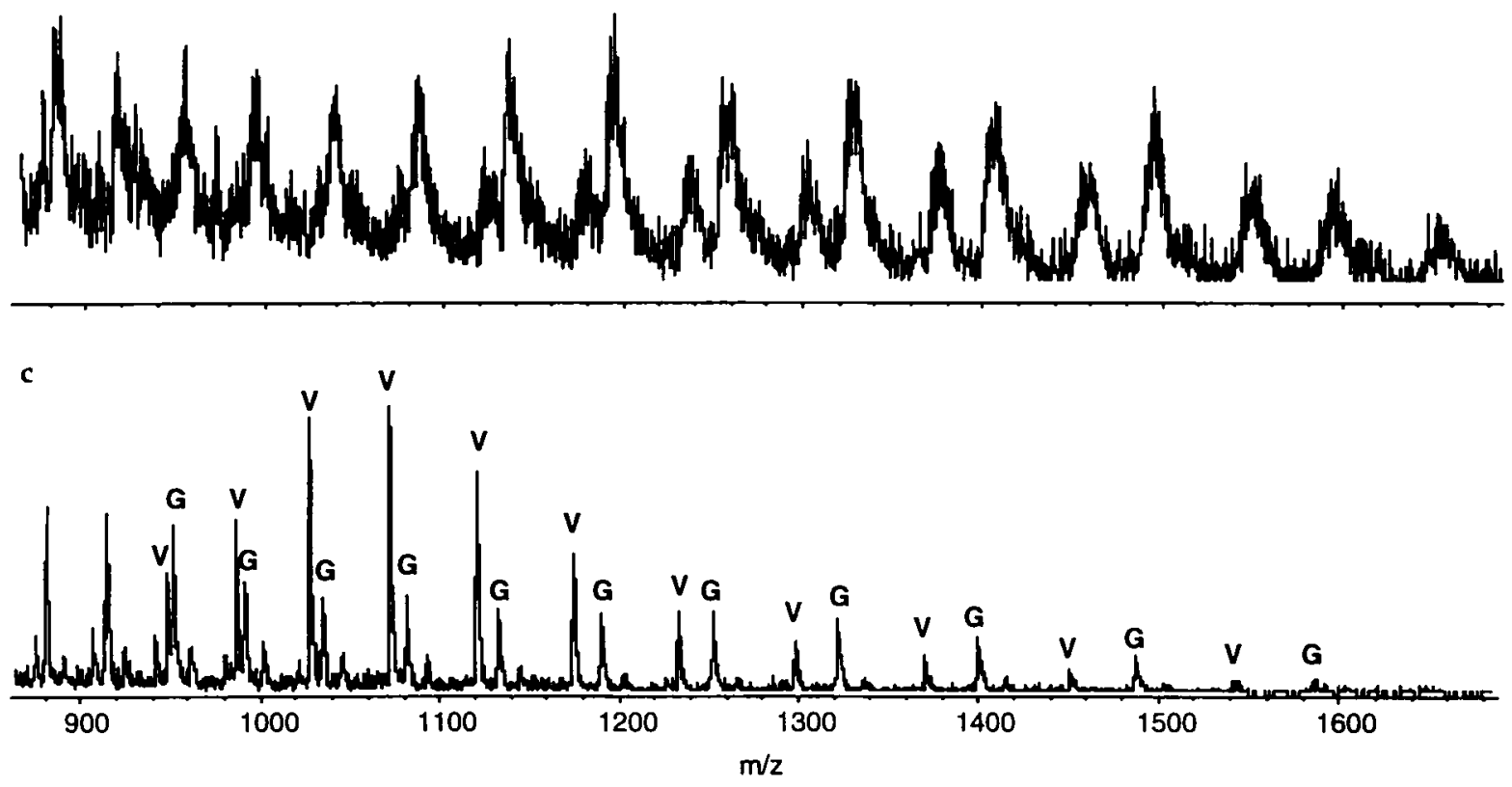

Figure 7. Electrospray mass spectra of a mixture of equimolar amounts of $t R N A^{G l y 1}$ (G) and $\mathrm{tRNA}^{\mathrm{Val1}}$ (V). (a) Ten microliters of $01 \%$ TEA added, (b) 1-nmol CDTA added, (c) 10- $\mu \mathrm{L} 01 \%$ TEA and 1-nmol CDTA added

mole percentage ranges. This is common for essentially all tRNAs from a variety of organisms [17]. From Table 3 , one also notes that molecular mass is related closely to chain length: almost no overlap among chain length exists [i.e., only Ile(CAU), a 76-mer, has a larger mass than some 77-mers]. Thus, the mass of a tRNA can be related to an intrinsic property of the tRNA.chain length. In addition, the values shown in Table 3 reveal that although tRNA size is biologically highly conserved, virtually all $E$. coli $\mathrm{tRNAs}$ can be distinguished or identified simply by molecular mass measured within $\pm 0.01 \%$. In those cases for which molecular masses differ by $2 \mathrm{u}$ or less [Ile(CAU)-His(GUC) and two Ile(GAU)s], identification can be made on the basis of modifications measured by HPLC or liquid chromatography mass spectrometry (LC/MS) of hydrolysates. As a more common example, the two Tyr(GUA) isoaccepting tRNAs differ from one another by only a $U \leftrightarrow A$ interchange in the sequence-represented by a mass difference of 23.04 in a total mass of $27,600 \mathrm{u}$ (or less than $0.1 \%$ of the total mass) - which readily can be distinguished by this method.

Interestingly, it is reasonable to postulate that any
tRNA of known sequence can be identified solely from a combination of its measured molecular mass and by qualitative identification of its modified nucleosides by chromatography or LC/MS of an enzymatic hydrolysate [30]. By conventional means, such identification would require sequencing, and experiments to establish the identity of the amino acid with which the tRNA can be charged. In the case of RNAs that are not modified (such as bacterial $5 S$ ribosomal RNA), identification can in general be made simply from molecular mass in comparison with the value required by the corresponding gene sequence. Contrary to tRNA, many ribosomal RNAs have not been sequenced at the RNA level, but many rRNA gene sequences are readily available from database collections [18]. On the other hand, in rare cases in which $5 S$ rRNAs are modified (e.g., [31]), modification could be detected from shifts in mass that are not predicted from the gene sequence, as in the case of smaller oligonucleotides [32]. This approach could be applied to account for the total tRNA modification (see Modification mass column in Table 3) if the corresponding gene sequence were known. 
a

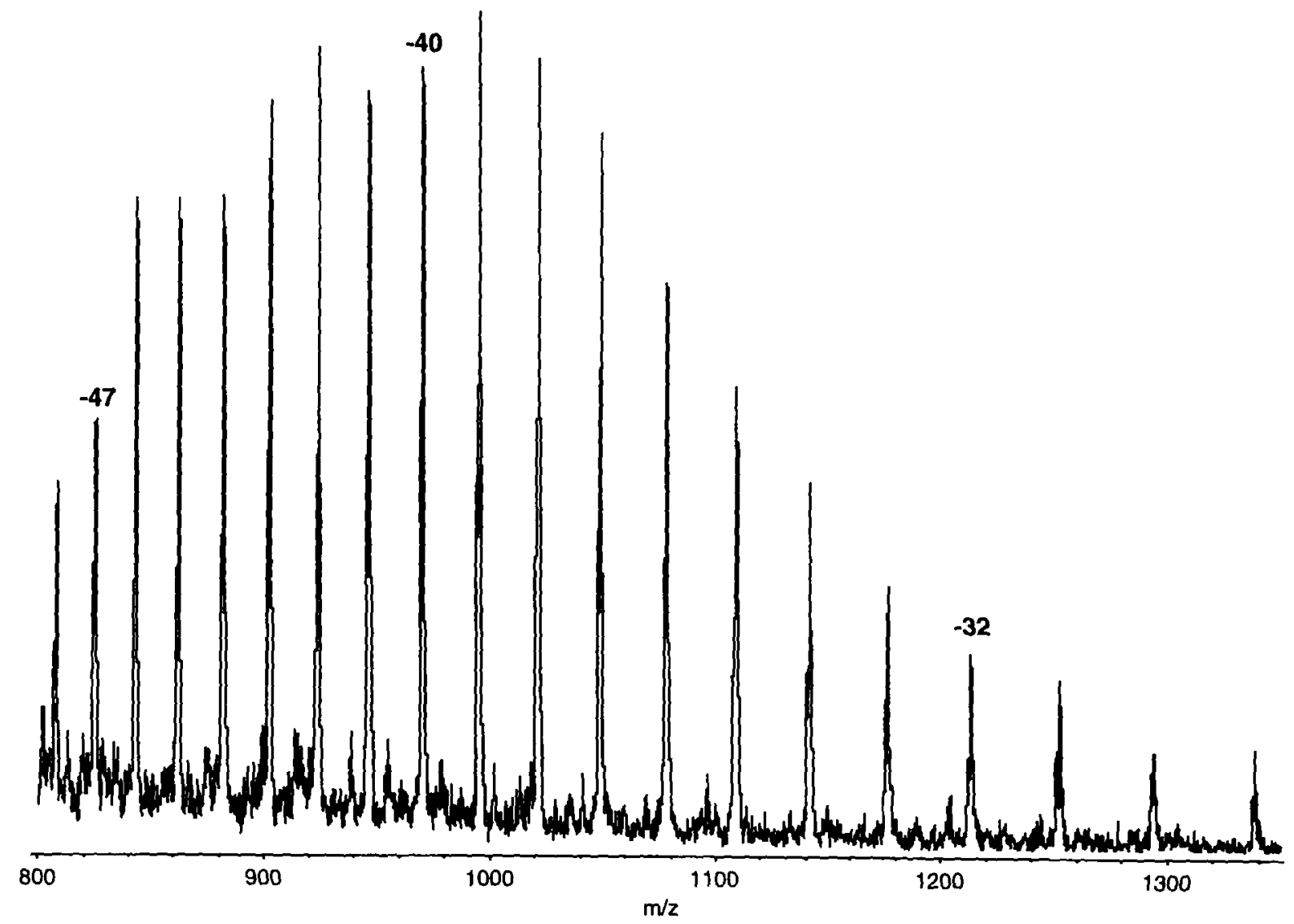

Mr calculated: $38,814.36$

$38,853.40$

b

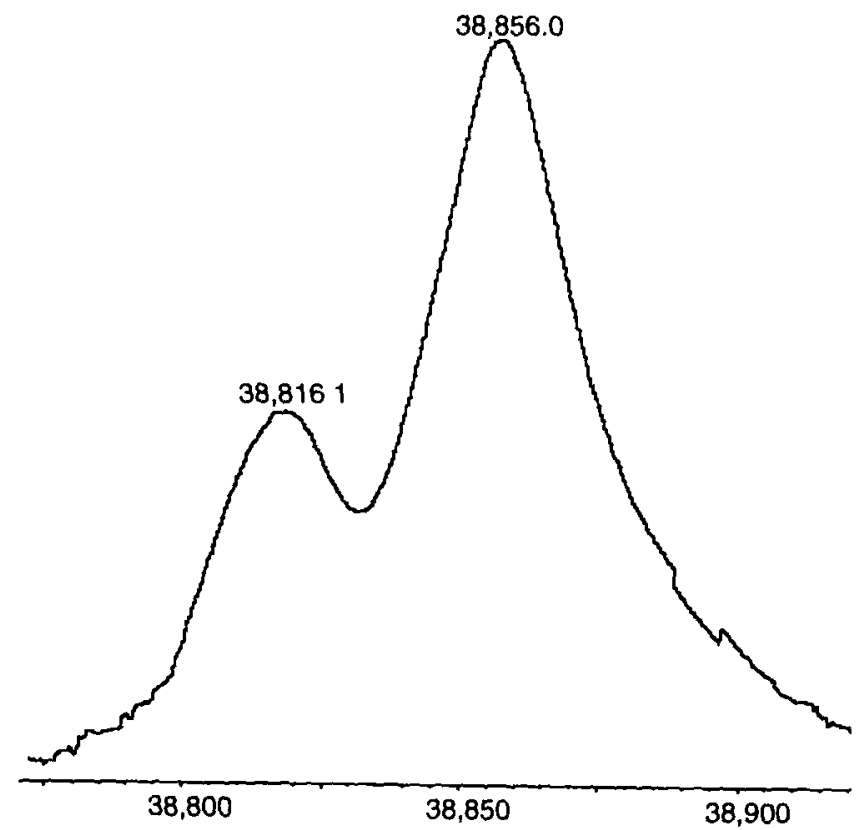

c

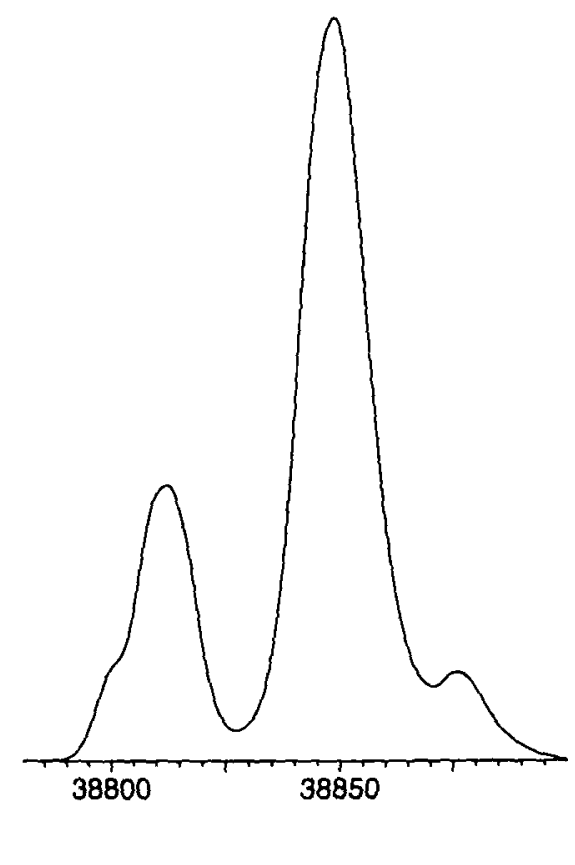

Figure 8. (a) Electrospray mass spectrum of E. coll $5 S$ rRNA (b) Transformed molecular mass spectrum. (c) MaxEnt derived molecular mass spectrum Table 2 contains calculated and found molecular masses and corresponding mass errors. 
Table 3. Molecular weights of $E$. coll class I and class II tRNAs including mass component due to modification and chain length

\begin{tabular}{|c|c|c|c|}
\hline $\begin{array}{l}\text { tRNA } \\
\text { (anticodon) }\end{array}$ & $M_{\mathrm{r}}$ & $\begin{array}{c}\text { Modification } \\
\text { mass }\end{array}$ & $\begin{array}{l}\text { Chain } \\
\text { length }\end{array}$ \\
\hline Cys (GCA) & 23,66144 & 148.34 & 74 \\
\hline Gly (CCC) & 23,81136 & 3211 & 74 \\
\hline Gly (UCC) & $24,01236^{a}$ & 1403 & 75 \\
\hline GIn (CUG) & 24,19766 & 7419 & 75 \\
\hline GIn (UUG) & $24,21472^{\circ}$ & 9026 & 75 \\
\hline Glu (UUC) & 24,22371 & 8719 & 75 \\
\hline $\operatorname{Arg}(\mathrm{CCU})$ & 24,27967 & 177.22 & 75 \\
\hline Lys (UUU) & 24,47389 & 33946 & 76 \\
\hline Glu (UUC) & $24,528.89$ & 8719 & 76 \\
\hline Glu (UUC) & 24,54489 & 8719 & 76 \\
\hline Gly (GCC) & 24,57579 & 3410 & 76 \\
\hline Ala (GGC) & 24,60381 & 1604 & 76 \\
\hline Ala (UGC) & 24,64283 & 10411 & 76 \\
\hline Val (UAC) & 24,68096 & 13420 & 76 \\
\hline Ala (UGC) & 24,68992 & 12017 & 76 \\
\hline $\operatorname{Trp}(\mathrm{CCA})$ & 24,70410 & 17841 & 76 \\
\hline $\operatorname{Arg}(A C G)$ & 24,71110 & 17034 & 76 \\
\hline Thr (GGU) & 24.75096 & 19324 & 76 \\
\hline Phe (GAA) & 24.81120 & 26347 & 76 \\
\hline Asn (GUU) & 24,81607 & 31942 & 76 \\
\hline Met, (CAU) & 24,89611 & 4614 & 77 \\
\hline Met, (CAU) & 24,92613 & 6016 & 77 \\
\hline lle (CAU) & 24.94528 & 43657 & 76 \\
\hline HIs (GUG) & 24,94610 & 19035 & 77 \\
\hline $\operatorname{Arg}(C C G)$ & 24,96114 & 6218 & 77 \\
\hline Val (GAC) & 24,99515 & 15329 & 77 \\
\hline $\operatorname{Arg}(A C G)$ & 25,02424 & 16427 & 77 \\
\hline $\operatorname{Arg}(U C U)$ & $25,02814^{\mathrm{a}}$ & 17521 & 77 \\
\hline Val (GAC) & 25,04019 & 15329 & 77 \\
\hline Asp (GUC) & 25,06922 & 19035 & 77 \\
\hline Met (CAU) & 25,14636 & 35447 & 77 \\
\hline Ile (GAU) & 25,19726 & 27831 & 77 \\
\hline Ile (GAU) & 25,19927 & 28032 & 77 \\
\hline Tyr (GUA) & 27,63595 & 28449 & 85 \\
\hline Tyr (GUA) & 27,65899 & 28449 & 85 \\
\hline Leu (CAG) & $28,14294^{c}$ & 3410 & 87 \\
\hline Leu (GAG) & $28,19197^{\mathrm{c}}$ & 3410 & 87 \\
\hline Leu (AAA) & $28,30128^{d}$ & 162.36 & 87 \\
\hline Ser (GGA) & 28,55324 & 3007 & 88 \\
\hline $\operatorname{Ser}(G G A)$ & 28,57230 & 4815 & 88 \\
\hline Ser (UGA) & 28,75759 & 25043 & 88 \\
\hline Ser (CGA) & 29,28289 & 14428 & 90 \\
\hline Ser (GCU) & $30,321.44$ & 19329 & 93 \\
\hline
\end{tabular}

a $N$ in sequence is modified $U$ calculated as $U$ only

- $N$ in sequence is probably $s^{2} U$ calculated as $s^{2} U$

${ }^{c} N$ in sequence is modified $G$ calculated as $G$ only

${ }^{d} \mathrm{~N}$ in sequence is modified $\mathrm{A}$ calculated as $\mathrm{A}$ only

As discussed in a recent paper [19], accurate mass measurement of oligonucleotides is useful, in some cases, for direct determination of the composition of the oligonucleotide. As shown in Table 4 for tRNAs, as the accuracy of the mass measurement is improved,
Table 4. Calculated nucleoside compositions possible withun a specified mass range around $M_{r} 24,680.96 \mathrm{u}$ (tRNA ${ }^{\text {Vali }}$ )

\begin{tabular}{|c|c|c|c|c|c|}
\hline \multirow[b]{2}{*}{ Chaın length } & \multicolumn{5}{|c|}{ Search range around molecular mass } \\
\hline & $\pm 2.0 u$ & $\pm 10 u$ & $\pm 05 u$ & $\pm 025 u$ & $\pm 010 u$ \\
\hline 72-mers & 13 & 7 & 3 & 3 & 1 \\
\hline 73-mers & 48 & 27 & 14 & 9 & 5 \\
\hline 74-mers & 93 & 46 & 24 & 15 & 7 \\
\hline 75-mers & 147 & 66 & 32 & 19 & 9 \\
\hline 76-mers & 179 & 90 & 45 & 26 & 11 \\
\hline 77-mers & 188 & 97 & 48 & 30 & 13 \\
\hline 78-mers & 170 & 88 & 43 & 23 & 11 \\
\hline 79-mers & 118 & 61 & 29 & 17 & 8 \\
\hline 80 -mers & 37 & 19 & 5 & 3 & \\
\hline Total $^{\mathrm{a}}$ & 993 & 501 & 247 & 147 & 68 \\
\hline \multicolumn{6}{|l|}{ Mınımum } \\
\hline composition $^{b}$ & 51 & 25 & 12 & 12 & 6 \\
\hline
\end{tabular}

${ }^{a}$ Total number of possible compositions without knowledge of chain length

${ }^{b}$ Constraints on minımum composition are $C \geq 14, U \geq 4, A \geq 6$. $G \geq 14$ Values in this row were calculated for 76 -mer by using these composition constraints

the possible compositional isomers become fewer and, if other information about the nucleic acid in question is known, can be reduced to a very manageable number. For instance, if chain length is known (see earlier discussion), then the compositional choices are reduced by at least $80 \%$, and in most cases even more. Because most tRNAs have well defined composition ranges of the four major nucleosides, even more rigorous constraints on the possible composition may be employed. For all class I E. coll tRNAs, there are at least 18 cytıdines, 8 uridines, 10 adenosines, and 18 guanosines [17]. For example, by using a minimum composition rule of 14 cytidines, 4 uridines, 6 adenosines, and 14 guanosines (applicable to all tRNAs), combined with knowledge of a chain length of 76 from the mass measurement itself, $E$. coll tRNA ${ }^{\text {val1 }}$ measured with an accuracy of $\pm 2 u$ has 51 possible compositional ssomers out of an initial value of 993 . In this hypothetical example, tRNA modification is ignored; in practice, the modification mass component can be established from LC/MS analysis [30].

Improvements in the mass measurement reduces possible choices to less than 15 , thus simplifying any possible sequence determination scheme that must ultimately accommodate one of the possible candidates. When employed as part of a sequencing strategy in which masses of subunits obtained by selective cleavage are measured, the number of allowable composition candidates would drop sharply as individual subunit compositions become known. Although mass spectrometers with higher resolving powers and more accurate mass measurement capabilities potentially can reduce the possible compositional isomers even further [10], the statistical absence of the all-light isotopic species requires that selection of an isotope peak of known heavy isotope composition be used for accurate 
calculation of molecular mass [33]. On the other hand, centrold measurement of the full isotopic cluster at relatively low resolving power leads to molecular mass values of good accuracy when cation adduction is sufficiently reduced.

\section{Conclusions}

Accurate molecular mass measurement of small nucleic acids by electrospray mass by spectrometry with errors of less than $0.01 \%$ has been demonstrated by using a simple quadrupole mass analyzer. The combination of conversion to the ammonium salt and addition of metal ion chelating agents and triethylamine allows for mass analysis of nucleic acids with accuracies as high as those found in protein measurements. The advantages of chemical methods over physical methods for salt removal include reduction of sample loss, as well as the ease of use and minimal sample preparation time. Accurate mass measurements of nucleic acids simplify identification of known (or suspected) sequence candidates and provide a rapid means for simplifying identification of unknown nucleic acids. The procedures reported should be equally applicable to synthetic polynucleotides (DNA or RNA) from the 10 through at least the 120 nucleotide size range.

\section{Acknowledgments}

The authors thank E. Bruenger and J A. Kowalak for the isolation of the $E$ colt $5 S$ rRNA and S C. Pomerantz for assistance with some of the molecular weight calculations We thank Professor Fred McLafferty and co-workers for a preprint of ref $10 \mathrm{We}$ also thank G. Giancarlo at Sciex for providing the NetCDF converted files This work was supported by the National Institutes of Health through grant GM 21584

\section{References}

1. Crain, P F Mass Spectrom Rev 1990, 9, 505-554

2 McCloskey, J. A., Crain, P F. Int. J. Mass Spectrom. Ion Processes 1992, 118/119, 593-615

3 Nordhoff, E., Ingendoh, A, Cramer, R., Overberg, A, Stahl, B ; Karas, M., Hillenkamp, F, Crain, P. F. Rnpud Commun Mass Spectrom. 1992, 6, 771-776

4 Smith, R D.; Loo, J A., Edmonds, C. G; Barınaga, C J, Udseth, H. R. Anal. Chem 1990, 62, 882-899

5. Fenn, J B., Mann, M , Meng, C. K., Wong, S. F., Whitehouse, C M Mass Spectrom. Rev. 1990, 9, 37-70.

6. Covey, T. R., Bonner, R. F.; Shushan, B. I ; Henion, J Rapid Commun. Mass Spectrom. 1988, 2, 249-256

7 Grotahn, L, Blocker, H.; Frank, R Biomed. Mass Spectrom $1985,12,514-524$
8. Stults, J. T.; Marsters, J. C Rapid Commun. Mass Spectrom. 1991, 5, 359-363.

9. Manıatıs, T., Fritsch, E. F., Sambrook, J. Molecular Cloning. A Laboratory Manual; Cold Spring Harbor Laboratory Press. Cold Spring Harbor, NY, 1982, pp 461-462.

10 Little, D. P.; Chorush, R. A; Speir, J. P.; Senko, M. W.; Kelleher, N. L.; McLafferty, F. W. J. Am. Chem Soc. 1994, 116, 4893-4897.

11 Pieles, U.; Zurcher, W.; Schar, M.; Moser, H. E Nucletc Acids Res 1993, 21, 3191-3196.

12 Gait, M J., Ed Oltgonucleotıde Synthests, Oxford University Press. New York, 1990.

13. Caruthers, M H., Beaton, G, Wu, J V ; Wiesler, W. Methods Enzymol. 1992, 211, 3-20

14 Connolly, B. A. Methods Enzymol. 1992, 211, 36-53

15. Sambrook, J.; Fritsch, E F., Manuatıs, T Molecular Cloning. A Laboratory Manual, Cold Spring Harbor Laboratory Press. Cold Spring Harbor, NY, 1989.

16. Ferrige, A. G, Seddon, M J ; Green, B. N.; Jarvis, S. A., Skilling, J Rapid Commun Mass Spectrom. 1992, 6, 707-711.

17 Steınberg, S., Misch, A., Sprınzl, M. Nucleic Acıds Res. 1993, 21, 3011-3015.

18 Specht, T., Wolters, J , Erdmann, V A Nucleic Acids Res. 1991, 19 (suppl), 2189-2191.

19 Pomerantz, S C.; Kowalak, J A, McCloskey, J. A J. Am. Soc. Mass Spectrom 1993, 4, 204-209

20 Teeter, M M.; Quigley, G J., Ruch, A In Metal Ions in Genetıc Information Transfer, Eichhorn, G. L.; Marzill, L. G., Eds., Elsevier/North-Holland New York, 1981; Vol 3, pp 233-272.

21 Farrell Jr, R. E F. RNA Methodologies A Laboratory Guide for Isolation and Characterization; Academic Press San Diego, CA, 1993, pp 48-50

22 Davis, L G., Dibner, M D.; Battey, J. F. Basic Methods in Molecular Biology, Elsevier New York, 1986; pp 323.

23. Farrell Jr, R. E. F RNA Methodologies A Laboratory Gude for Isolation and Characterization, Academic Press San Diego, CA, 1993, pp 32-39

24. Cohn, M.; Danchin, A, Grunberg-Manago, M / Mol. Biol. 1969, 39, 199-217

25. Romer, R., Hach, R. Eur. J. Biochem 1975, 55, 271-284.

26. Stein, A.; Crothers, D M Biochenustry 1976, 15, 157-160.

27. Dean, J A., Ed Lange's Handbook of Chemistry, 13th ed, McGraw-Hill New York, 1985; pp 5-77-5-91.

28 Phillips, D. R, McCloskey, J. A. Int. J. Mass Spectrom. Ion Processes 1993, 128, 61-82.

29 Atkinson, T., Smith, M In Oltgonucleotide Synthesis. A Practical Approach, M. J. Gait, Ed, Oxford University Press New York, 1984, p 69.

30. Pomerantz, S C., McCloskey, J A. Methods Enzymol. 1990, $193,796-824$

31. Bruenger, E.; Kowalak, J A, Kuchino, Y; McCloskey, J. A.; Mizushıma, H, Stetter, K O., Crain, P. F. FASEB J. 1993, 7, 196-200.

32 Kowalak, J. A., Pomerantz, S C, Crain, P. F.; McCloskey, J A. Nucleic Acids Res 1993, 21, 4577-4585.

33 Beu, S. C.; Senko, M. W., Quinn, J. P, McLafferty, F. W. I Am. Soc. Mass Spectrom 1993, 4, 190-192. 